\title{
Diálogos entre Paul Ricoeur e Turismo Cultural
}

\author{
Diálogos entre Paul Ricoeur y el Turismo Cultural
}

Dialogues between Paul Ricoeur and Cultural Tourism

\author{
Renan Costa Valle Scarano ${ }^{1}$ \\ Alice Leoti ${ }^{2}$
}

\begin{abstract}
Resumo
O presente trabalho busca fazer uma aproximação entre filosofia e turismo, por intermédio de uma abordagem hermenêutica do turismo cultural, a partir da óptica do filósofo francês Paul Ricoeur. O turismo cultural lida com a relação entre o turista e comunidade local receptora. A filosofia de Ricoeur oferece uma possibilidade de interpretação da cultura através da hermenêutica dos símbolos. A metodologia empregada foi de uma pesquisa teórica/ bibliográfica abordando as temáticas de filosofia, turismo e cultura.
\end{abstract}

Palavras-chave: Aproximação, Filosofia, Paul Ricoeur, Turismo Cultura.

\section{Resumen}

Este trabajo pretende acercar la filosofía y el turismo por medio de un abordaje hermenéutica del turismo cultural a partir del pensamiento del filósofo francés Paul Ricoeur. El turismo cultural trata de la relación entre el turista y la comunidad local que es receptora. La filosofía de Ricoeur ofrece una posibilidad de interpretación de la cultura mediante la hermenéutica de los símbolos. La metodología utilizada fue una pesquisa teórica/bibliográfica para tratar de la filosofía, el turismo y la cultura.

Palabras clave: Aproximación, Filosofía, Paul Ricoeur, Turismo Cultural.

\section{Abstract}

The present work seeks to make an approximation between philosophy and tourism, through a hermeneutic approach of cultural tourism, from the perspective of the French philosopher Paul Ricoeur. Cultural tourism deals with the relationship between the tourist and the local receiving community. Ricoeur's philosophy offers a possibility of interpreting culture through the hermeneutics of symbols. The methodology used was a theoretical I bibliographical research addressing the themes of philosophy, tourism and culture.

Keywords: Approach, Philosophy, Paul Ricoeur, Turismo Cultural.

\section{Introdução}

O presente trabalho busca uma aproximação entre a filosofia de Paul Ricoeur (19132005) e o Turismo Cultural através do viés hermenêutico. Para alcançar tal propósito, pretende-se realizar uma abordagem do turismo cultural a partir da perspectiva filosófica

\footnotetext{
${ }^{1}$ Mestre em Política Social pela Universidade Católica de Pelotas (2016); Especialista em Direitos Humanos pela Universidade Federal do Pampa (UNIPAMPA) (2013); Bacharel e licenciado em Filosofia pela Universidade Católica de Pelotas (2011). Atualmente é aluno especial do PPG Ciência Política da Universidade Federal de Pelotas.

${ }^{2}$ Mestra em Memória Social e Patrimônio Cultural pela Universidade Federal de Pelotas (2013); Especialista em Gestão Pública e Desenvolvimento Regional pela Universidade Federal de Pelotas (2012); Bacharela em Turismo pela Universidade Federal de Pelotas (2009).
} 
ricoueriana onde, o outro, aparece como uma preocupação filosófica. Uma das preocupações centrais do pensamento de Ricoeur é: Como dar lugar ao outro? A partir de então, a cultura e o turismo cultural podem ser vistos como áreas em que emerge o outro. Nesse sentido, o pensador compreende linguagem e símbolo como meios de acesso ao outro. Devido a isso, acredita-se que Ricouer possa contribuir para que o significado da existência humana seja elucidado através da compreensão.

O presente trabalho está estruturado da seguinte forma: na primeira parte, busca-se apresentar o Turismo Cultural como forma de aproximação do outro. A prática do turismo cultural pode ser uma forma de conhecer a cultura do outro. Enquanto fenômeno social o turismo tem como escopo conhecer outras sociedades. No segmento turismo cultural, o indivíduo viajante - o turista - deseja visitar monumentos, esculturas, museus, festivais, feiras e qualquer outro tipo de manifestação cultural que o faça interpretar e conhecer a cultura a qual está visitando. Num segundo momento, pretende-se expor o pensamento de Paul Ricoeur, suas influências e suas ideias. Além disso, enfatiza-se que a linguagem aparece como o centro da obra ricoeuriana, nesse sentido, denota-se que a hermenêutica é vista como a via de interpretação dos significados e sentidos que estão contidos e são expressos nos símbolos, nos sinais, na cultura, como forma indireta de acesso ao ser humano.

A metodologia utilizada neste trabalho foi baseada em uma pesquisa bibliográfica acerca do entendimento antropológico de cultura, compreendendo-a a partir da concepção simbólica. Ainda, buscou-se em teóricos a noção de turismo cultural e como este faz uso dos símbolos culturais. Finalmente, tentou-se a partir da óptica de Paul Ricoeur e sua concepção da linguagem simbólica como fator essencial de acesso ao sentido do humano, ligar a perspectiva do turismo cultural com a filosofia, a partir da hermenêutica. A relevância deste trabalho se dá numa tentativa de contribuir para que os estudos entre filosofia e turismo se relacionem.

\section{A cultura como expressão da linguagem humana}

Fabietti (apud BARUFFA, 2005, p.36) define cultura como "uma maneira particular do homem, como membro de uma sociedade, de organizar seu pensamento e seu comportamento com relação ao ambiente". Nesse processo de organização o homem precisa da cultura para transformar-se em humano, portanto, Baruffa (2005) defende a ideia de que a espécie do Sapiens Sapiens, é naturalmente incompleta. Segundo ele, "o sapiens sapiens elabora formas de comportamento que prescindem, em grau variável, dos instintos, tendo neles um condicionamento parcial porque controlado culturalmente" (BARUFFA, 2005, 
p.36). Nesse processo, argumenta Baruffa (2005), o ser humano é o criador e a criatura da cultura.

A palavra cultura provém do termo colere que significa cultivar, o ser humano precisa ser cultivado, precisa ser inserido no contexto social, senão, ele não se torna ser humano.

\begin{abstract}
A criação cultural fornece ao homem os meios físicos e os instrumentos para a sua inserção na variabilidade ambiental: a tecnologia. Condiciona as modalidades pelas quais os indivíduos interagem entre si: a organização social. Oferece uma explicação do mundo e da sua própria existência, elaborando crenças e valores: a religião e a ética. Favorece a compreensão das leis que governam a realidade física e biológica: a ciência (BARUFFA, 2005, p.36).
\end{abstract}

Cada cultura passa valores e esses valores culturais criam padrões de comportamento. Portanto, o ser humano, aparece nessa visão como um produto da cultura e um transmissor da mesma, sua personalidade é construída culturalmente. Já Geertz (2008), salienta o aspecto simbólico da cultura. Nesse sentido, o sistema simbólico expressa as relações de determinada comunidade.

Acreditando, como Max Weber, que o homem é um animal amarrado a teias de significados que ele mesmo teceu, assumo a cultura como sendo essas teias e a sua análise; portanto, não como uma ciência experimental em busca de leis, mas como uma ciência interpretativa, à procura do significado (GEERTZ, 2008, p.4).

Dessa forma, Clifford Geertz insere um componente importante na discussão sobre cultura, ele sugere que o comportamento humano é uma "ação simbólica" (GEERTZ, 2008, p.8), e como tal, precisa ser interpretada. Os símbolos são mediações que os seres humanos desenvolvem para comunicar algo. Um símbolo pode ser a língua utilizada para comunicação entre os nativos ou também os valores que guiam as pessoas. Em seu estudo sobre os símbolos, Ricoeur aponta algumas considerações a respeito dessa linguagem. De acordo com Wicks (2005), o filósofo francês, ao abordar o símbolo se depara com três zonas de emergência. O símbolo,

surge, en primer lugar, en los mitos y ritos relacionados con las manifestaciones de lo sagrado o hierofanías cósmicas, de los que se ocupa la fenomenología de la religión; luego, con los fantasmas que pueblan nuestros sueños, estudiados por el psicoanálisis; finalmente, en la poesía, entendido el término en su sentido más amplio, como poiésis, como creación artística, de la que se ocupa la poética (WICKS, 2005, p. 47).

Ainda sobre cultura, Pesavento (2006, p.46), afirma que a cultura é uma tradução do mundo em significados. Pois ela, é "uma produção social histórica a se expressar, através do 
tempo, em valores, modos de ser, objetos, práticas (...)". Portanto, se a evolução biológica, resultou no processo de hominização, "a cultura junta a "humanização"” (BARUFFA, 2005, p.36, grifo o autor).

A cultura, além de produzir valores, ela também se dá a tarefa de passar os valores para outras gerações. A maneira de ver o mundo, de experenciá-lo, a forma de ver o outro e de se ver inserido no ambiente das relações humanas de uma comunidade, enfim, tudo isso é produzido culturalmente. No entanto, os valores são relativos, pois aquilo que possui importância para um povo, pode não ser para outro. Logo, a cultura não é universal, pois não existe uma cultura, mas várias perspectivas culturais.

Nesse pluriculturalismo é inevitável que haja conflitos culturais, pois na medida em que há muitas formas de organização social, como, várias concepções de família, de clã, de comunidade, de Estado, de religião, de línguas diferentes, de formas de produzir os bens necessários para a sobrevivência humana, etc., enfim, muitas formas que dão sentido e que expressam a busca humana por conferir sentido ao seu mundo. Deste modo, o ser humano é inserido na cultura e nesse mundo simbólico, sua resposta, pode ser de adaptação ou não, além do mais, sua resposta diante do outro pode ter um caráter solidário, que reconheça a alteridade do outro ou etnocêntrico.

A cultura não é um conceito estático, ao contrário, trata-se de um horizonte onde há transformações e essas, acontecem em relação a inúmeros fatores, desde sociais, econômicos, religiosos ou outros. Nesse processo dinâmico de construção cultural podem existir conflitos culturais, seja em civilizações ou etnias que enfrentam processos de deslocamento de seu habitat e/ou de migração.

Porém, o ato de deslocar-se territorialmente, também pode implicar uma curiosidade de uma existência além de seu horizonte. Assim sendo, ao descobrir as possibilidades de deslocamento para lugares cada vez mais distantes, o homem passou a planejar meios e formas de viajar sem suscitar desconfianças e a fim de garantir provimento as suas necessidades alimentares, de repouso e de transitar pacificamente (ANDRADRE, 2008).

\section{Origens e interações a partir do Turismo Cultural}

Há um consenso entre os autores da área de turismo em afirmarem que os termos turismo e turista originam-se das palavras francesas TOURISME e TOURISTE. No entanto, ressalva-se que na língua portuguesa, os termos turismo e turista foram adotados do inglês e não diretamente da matriz francesa. O termo TOUR foi usado pela primeira vez em 1760, na Inglaterra. A matriz do radical TOUR é o latim, através do substantivo TORNUS, do verbo 
TORNARE, cujo significado é "giro, volta, viagem ou movimento de sair e retornar ao local de partida".

A relação entre turismo e cultura surge no Grand Tour europeu. A expressão Grand Tour remete as viagens realizadas por jovens europeus que tinham como objetivo complementar a sua formação cultural. Os filhos das famílias abastadas, inglesas, eram enviados a países estrangeiros a fim de aprender uma ou duas línguas, tendo o escopo de conhecer e distrair-se. Tal viagem, significava a oportunidade do jovem de ter contato direto com monumentos, ruínas e obras-de-arte, especialmente dos antigos gregos e romanos. Para realizar as viagens, cada viajante era acompanhado de um tutor, que muitas vezes era alguém conhecia muitas culturas. O Grand Tour tem sua origem no século XVII, mas atingiu seu auge nos séculos XVIII e XIX, sendo impulsionados pelo advento da ferrovia em grande escala. Posteriormente, as viagens se expandiram para além do continente europeu, usando-se também de navios a vapor para visitar, por exemplo, o continente americano. Portanto, a realização do Grand Tour era um modo de detenção da cultura, visto que o acesso a ela era extremamente limitado.

Pode-se dizer que o Grand Tour remonta a origem histórica do turismo contemporâneo, a relação cultura e turismo é uma das principais motivações para uma viagem. O entendimento ocidental de cultura compreende uma rede de conhecimentos, crenças, arte, lei, costumes, hábitos desenvolvidos pelo ser humano enquanto ser social. Assim, todo o modo de fazer e o fazer humano de uma sociedade, suas formas de expressão bem como modo de vida, coadunem em um conjunto da produção humana, expressando a noção de cultura. O indivíduo participante do Grand Tour ajudou a propagar uma concepção de turismo cultural, onde o viajante é apreciador de culturas antigas e paisagens com valoração estética para a sociedade.

Nesse contexto, observa-se que a cultura é objeto de desejo do turista há séculos. Porém, como afirma Pérez (2009, p. 108):

\footnotetext{
Ainda que a natureza cultural do turismo é já antiga, a ligação entre turismo e cultura é relativamente recente e muito mais o conceito de "turismo cultural". Os profissionais da cultura tendiam, até há pouco tempo, a minusvalorar o turismo porque entendiam-no como uma actividade banal, superficial, aculturadora e com pouco interesse pela cultura visitada. Isto mudou muito nas últimas décadas com a criação de pontes entre um campo e outro.
}

Já Donaire (2012) afirma que turismo cultural é uma mistura entre turismo e cultura e que, por se tratar de dois espaços em contato, todavia é um conceito impreciso. Nesse viés, o 
autor defende que a experiência turística, "es una de las experiencias posibles que relacionan a los individuos con las varias manifestaciones culturales”. Nessa relação que o turismo cultural proporciona, há uma interação transcendental e mística, enquanto que o turismo, por outro lado, proporciona através da curiosidade, da transgressão e da sedução uma forma de encontro com o outro. Portanto, turismo cultural é um espaço de fronteira onde há uma confluência dessas duas áreas.

O turismo é uma das atividades que mais proporciona a interação cultural entre os diferentes povos e etnias. Dessa forma, a atitude de abertura da pessoa é imprescindível para que ela possa experimentar uma nova cultura, isso significa, adentrar ao mundo do outro, não somente pelo conhecimento inteligível, mas pela valorização da experiência. A movimentação de indivíduos por territórios diferentes ao seu de residência, ou seja, a prática turística, pode ser compreendida como uma atividade cultural. Para isso, é preciso que o ser humano esteja aberto ao conhecimento de novas culturas, pois, ir ao encontro de outrem, requer, não apenas conhecer novos lugares e povos, mas apreender o significado, captar a linguagem que é transmitida e expressa por tal cultura. Essa atitude, pressupõe o respeito pelo outro e sua manifestação.

O turismo é permeado pela cultura, assim como a noção de cultura, turismo cultural, também é definido de diferentes formas pelos estudiosos da área. Nesse sentido, Pérez (2009, p. 108), sugere que "turismo pode ser entendido como um acto e uma prática cultural, pelo que falar em "turismo cultural" é uma reiteração. (...). Em termos filosóficos toda a prática turística é cultural".

O turismo cultural remete a experiências sensoriais, que vão desde uma experimentação gastronômica a assistir um festival folclórico, e que pode passar pela contemplação de um bem cultural edificado, ou ainda, uma paisagem cultural. Pérez (2009, p. 110) corrobora nesse sentido ao dizer que

A experiência turística integra vivências sensuais (sons, odores, cores, ambiente), sociais (relações com os outros, hospitalidade, bem-estar, segurança, diversão), culturais (eventos, festivais, actividades, alojamento, restauração, enriquecimento) e económicas (relação qualidade do serviço-preço, relação custo/benefício da vivência, acessibilidades e transportes).

Destarte, vivenciar a cultura do outro por intermédio do turismo, abarca a experimentação de determinado momento, neste caso a viagem, de modo que o mesmo tenha um significado profundo. Portanto, "turismo cultural é uma vivência de participação em novas 
e profundas experiências culturais estéticas, intelectuais, emocionais e psicológicas" (PÉREZ, 2009, p. 109-110).

Alguns aspectos são comuns a maior parte das definições de turismo cultural, como a motivação cultural, a necessidade de vivenciar novas culturas, novas experiências e de conhecer o outro. $\mathrm{O}$ ato de conhecer faz com que a cultura do outro seja inserida no conhecimento (memória) de alguém, o turista. E, o ato de conhecer novas sociedades, pode proporcionar um autoconhecimento, pois, ao conhecer o outro, o turista pode olhar para sua própria cultura, para seus costumes com um olhar de fora. Ao mesmo tempo também, esse ato de conhecer o outro, pode levar o sujeito a não se fechar em si, mas abrir-se para o novo.

Essa forma de turismo, se utiliza dos símbolos representantes de uma cultura como atrativo turístico, ou seja, aquilo que possui uma carga histórico-cultural suficiente para atrair os olhares dos turistas. Existe uma multiplicidade de possíveis atrativos turísticos, como por exemplo: peregrinações religiosas, sítios arqueológicos, sítios históricos, centro históricos, monumentos, museus, quilombos, lugares de acontecimentos históricos, lugares que recordam a vida de artistas ou intelectuais, ópera, dança, teatro, música, cinema, festivais, celebrações locais, ateliês, teatros, obras-de-arte, exposições, artesanato, produtos típicos, idioma, gastronomia típica, vestimenta, trajes, edificações especiais, arquitetura, ruínas, espaços e instituições culturais, casas de cultura, feiras, mercados tradicionais, saberes e fazeres, causos, trabalhos manuais, eventos programados, e outros que se enquadrem na temática cultural.

De acordo com o Avighi (2000), o turismo cultural busca a realização interior e dá ênfase ao meio ambiente e à compreensão da cultura e da história de outros lugares, querendo conhecer povos e se enriquecer culturalmente. Segala (2003, não paginado), elaborou a seguinte definição de turismo cultural:

\footnotetext{
O turismo cultural é motivado pela busca de informações, de novos conhecimentos, de interação com outras pessoas, comunidades e lugares, da curiosidade cultural, dos costumes, da tradição e da identidade cultural. Esta atividade turística tem como fundamento o elo entre o passado e o presente, o contato e a convivência com o legado cultural, com tradições que foram influenciadas pela dinâmica do tempo, mas que permaneceram; com as formas expressivas reveladoras do ser e fazer de cada comunidade. $\mathrm{O}$ turismo cultural abre perspectivas para a valorização e revitalização do patrimônio, do revigoramento das tradições, da redescoberta de bens culturais materiais e imateriais, muitas vezes abafadas pela concepção moderna.
}

A interação com uma determinada cultura significa um passo dado para conhecer o outro. Nesse sentido, o turismo cultural proporciona a possibilidade de ir ao encontro do outro, de conhecer outra cultura, de adentrar num mundo novo. Contrariamente a visão de turismo cultural como uma prática comercial, em que, as sociedades e comunidades são 
apresentadas às outras, dramatizando as particularidades locais de determinadas culturas, ou, expondo-as como produtos exóticos. Corroborando com esta perspectiva de turismo cultural, o antropólogo Manuel Delgado Ruíz analisa o turismo cultural da seguinte maneira. Para Ruíz (apud Pérez, 2009, p.116),

\begin{abstract}
...el turismo cultural se ha constituido en lugar privilegiado en el que operar análisis acerca de cómo las sociedades humanas se presentan ante otras sociedades y ante si mismas... el turismo cultural es una industria cuya materia prima es la representación dramatizada y en extremo realista, de cualidades que se consideran de algún modo inmanentes a determinadas agrupaciones humanas de base territorial -ciudades, regiones, países-, reificación radical de lo que de permanente y substantivo pueda presumir una entidad colectiva cualquiera.
\end{abstract}

Contrariamente a essa ideia de turismo cultural, visto a partir de uma óptica comercial, industrial e expositiva das culturas, acredita-se que, o turismo cultural, pode contribuir para a compreensão e para aproximação do outro. Nesse sentido, acredita-se ser possível aproximar essa prática do turismo com a filosofia de Paul Ricoeur. Pois, as culturas trazem uma linguagem simbólica em suas manifestações, são vias de acesso aos diferentes mundos construído pelos seres humanos. Nessa perspectiva, a hermenêutica corrobora na compreensão da linguagem humana que se manifesta em diversas expressões.

\title{
4 A filosofia de Ricoeur
}

Paul Ricoeur nasceu na cidade de Valence, na França, em 1913. Sua obra filosófica tem por influência o existencialismo de Gabriel Marcel (1889-1973) e de Karl Jaspers (18831969) e a fenomenologia de Edmund Husserl (1859-1938). A obra ricoeuriana trata de uma multiplicidade de temas que vão desde a literatura, do conhecimento, da psicanálise, do poder, da política, do símbolo além de outros. Sua filosofia combina a descrição fenomenológica e a interpretação hermenêutica.

Villaverde (2006), destaca quatro etapas que podem ser localizadas no percurso da obra de Paul Ricoeur. São elas: formação e influências, até 1950; etapa fenomenológica, dos anos 50 aos 60; etapa hermenêutica, dos anos 60 aos 90 e a etapa da filosofia prática, éticopolítica dos anos 90 até 2005. Há um tema que perpassa todas essas etapas, defendidas por Villaverde que é a existência humana e seus significados. Nessa perspectiva, François Dosse (2003, p.181), afirma que desde sua tese intitulada de Philosophie de la Volonté (1949), há um mote em sua filosofia, pois, Ricoeur não deixou de perseguir, “ não deixou de se colocar a questão do sentido da ação humana”. A partir de então pode-se concluir que a filosofia de Ricoeur pode ser caracterizada como uma filosofia reflexiva sobre a ação humana. 
A filosofia de Ricoeur pertence a uma tradição que pode ser localizada dentro da perspectiva ocidental aristotélica, agostiniana, cartesiana, kantiana e hegeliana. Nessa linha, sua filosofia "investiga la posibilidad de alcanzar la comprensión del sí mismo; ella hunde sus raíces en el "pienso luego soy" cartesiano, pero le integra los rasgos de una variante hermenéutica de la fenomenología husserliana, que incluye los aportes de Heidegger y Gadamer" (WICKS, 2005, p.44). Já em sua primeira grande obra intitulada "Philosophie de la Volonté I. Le volontaire et le involontaire”, de 1950, Ricoeur, “ (...) realiza una descripción fenomenológica de las estructuras de lo voluntario y lo involuntario" (VILLAVERDE, 2006, p.30). Sobre esta obra, Villaverde (2006, p.30) comenta que Ricouer argumenta que Husserl, "se olvida en su fenomenología de hacer gravitar la realidad empírica del hombre alrededor de la voluntad humana”. Em contraposição à Husserl, Ricoeur, através de uma abordagem fenomenológica do voluntário e involuntário, descreve os significados e estruturas essenciais da intenção, do projeto, do motivo, do desejo (VILLAVERDE, 2006).

$\mathrm{Na}$ etapa hermenêutica, sugere Villaverde (2006, p.31), "Ricoeur descubre la potencialidad semántica del lenguaje indirecto, característico de los discursos míticosimbólicos arcaicos, en el análisis que realiza de la "empírica de la voluntad" en $L a$ symbolique du mal, segunda parte de Finitud y Culpabilidad (1960)". Uma das ideias defendidas por Ricoeur, em sua etapa hermenêutica é que mito e símbolo são expressões da realidade que o ser humano se utiliza como formas de expressão. Nesse sentido, Villaverde (2006, p.32), sugere que no segundo volume de "Philosophie de la Volunté", Ricoeur, para “introducir el problema del mal en la estructura de la voluntad era preciso el rodeo de los símbolos y de los mitos", se utiliza da hermenéutica. A hermenéutica, se revela como o método "empírico-descriptivo necesario para analizar símbolos y mitos en los que se expresan múltiples modalidades sobre el problema del mal o de la culpa" (VILLAVERDE, 2006, p.32).

Dessa forma, a via hermenêutica é o caminho pela qual Ricoeur busca compreender os significados da existência humana e a realidade que é produzida pelo ser humano. É para compreender a existência humana que as reflexões filosóficas de Ricoeur se dão em torno do outro e da linguagem simbólica que emerge deste.

Franco (1995), na obra intitulada de "Hermenêutica e Psicanálise na obra de Paul Ricoeur", também sugere que o objetivo da obra riocueriana é "interpretar o homem: quem é o homem contemporâneo?", se questiona Ricoeur. Para isso, o filósofo francês, busca nos símbolos, no mito, na linguagem poética, os sinais que revelam o ser humano. O homem só se conhece indiretamente: por meio daquilo que ele deixa de impregnado em sua própria produção, não necessariamente de modo consciente (FRANCO, 1995, p. 25). A filosofia 
hermenêutica de Ricoeur visa "uma teoria geral da interpretação" afirma Shaefer (2008, p.60) parafraseando o filósofo de Valence. Trata-se da busca de sentido pela via da interpretação, como sugere Franco (1995, p.52). Nessa busca, procura-se desvelar o sentido humano e, nessa empreitada, a hermenêutica fornece as ferramentas para analisar e interpretar a linguagem humana.

\section{A hermenêutica como tentativa de compreensão o mundo humano}

Para Ricoeur a hermenêutica remete originariamente ao problema da compreensão. O horizonte em que se encontra a hermenêutica é mais amplo, pois trata-se "do problema fundamental de ordem filosófica acerca da compreensão, ou melhor, da possibilidade de compreensão das estruturas de significação" (SILVA, 2013, p.8). Villaverde (2006) analisa que em todas as etapas filosóficas de Ricoeur, seja na fenomenologia, na hermenêutica ou na ética, "su filosofía ha permanecido fiel a una antropología filosófica empeñada en desvelar el sentido del hombre, de su modo de manifestarse y de actuar" (VILLAVERDE, 2006, p.42). Ou seja, é em vista de compreender a linguagem humana que suas reflexões filosóficas se espraiam no mundo humano da linguagem, do símbolo e do comportamento.

Os seres humanos estão imersos num fluxo de linguagem, "num conjunto linguísticotemporal" (D’AGOSTINI, 2003, p.399). E, é nesse fluxo de linguagem que o ser humano experiencia a realidade que o circunda, porém, não de modo direto. D’Agostini (2003) ressalta que "jamais encontramos as coisas de modo imediato, mas temos sempre um certo número de informações preliminares, preconceitos, expectativas a seu respeito, e a linguagem determina, pré-orienta o nosso juízo sobre a realidade” (D’AGOSTINI, 2003, p.399).

Segundo Wicks (2005) Ricoeur, encontra na hermenêutica uma possibilidade de adentrar ao discurso da linguagem humana que, para ele,

\footnotetext{
no se cierra jamás sobre sí mismo, sino que siempre, en todos sus usos, pretende "decir" una experiencia, un modo de vivir y de estar en el mundo que lo precede y exige ser dicho y que apunta también -en ciertas formas del discurso- hacia nuevos modos posibles de ser en el mundo (WICKS, 2005, p.46).
}

Por isso, que Ricoeur refere-se ao símbolo, à metáfora como formas de linguagem que dizem o mundo ontológico do ser humano, essas formas de linguagem passam os limites da linguagem lógica. Nesse sentido, vale destacar a cultura como espaço privilegiado onde o ser humano produz significados para sua vida, mas também, espaço onde o ser humano expressa seu ser e sua história. 
O ser humano produz cultura, seu comportamento social é histórico e nessa perspectiva, ele precisa ser interpretado para ser compreendido em seu significado. A cultura aparece como uma expressão rodeada de símbolos que não são uma linguagem direta, pois o símbolo, enquanto linguagem humana não expressa um significado de antemão, ele precisa ser conhecido para ser compreendido. Analisando a questão do símbolo na obra de Ricoeur, Wicks (2005) comenta que:

el símbolo surge siempre en la intersección del lenguaje con algo que lo trasciende, que no es íntegramente logos y que, por consiguiente, no puede nunca llegar a ser enteramente traducido por la palabra; pero precisamente debido a dicha característica; el símbolo se constituye en algo "que da que pensar"; vale decir, exige una interpretación que -necesariamente, puesto que el símbolo incluye un núcleo indecible- se prolonga indefinidamente sin culminar jamás (WICKS, 2005, p.47).

Enquanto linguagem que transcende a compreensão lógico-racional, o símbolo comporta um núcleo que é essencialmente intraduzível, por isso que, o símbolo dá o que pensar. Em "O conflito das Interpretações" (1969), Ricoeur inicia o texto fazendo uma abordagem histórica da hermenêutica. $\mathrm{O}$ autor considera que a hermenêutica inicia seus estudos com a análise dos escritos sagrados.

Não é inútil lembrar que o problema hermenêutico se colocou primeiro que tudo nos limites da exegese, isto é, no quadro duma disciplina que se propõe compreender um texto, de o compreender a partir da sua intenção, sobre o fundamento daquilo que ele quer dizer (RICOEUR, 1978, p.5).

Assim como um texto deve ser interpretado para ser compreendido, a linguagem humana também necessita de interpretação. Hermenêutica, nessa óptica é a teoria que preside a interpretação de um texto. "Originalmente, o conceito de texto se prendia à noção de escritura sagrada. Hoje há um conceito de texto ampliado. O texto passa a ser todo conjunto coerente de signos suscetível de ser lido e interpretado (FRANCO, 1995, p.71).

$\mathrm{O}$ conceito de texto não se denota apenas ao texto escrito, mas a linguagem humana e esta, possui muitos significados. De acordo com Silva (2013), a hermenêutica, "foi primeiramente usada no domínio Teológico" para interpretar corretamente a Bíblia. Nesse sentido, a hermenêutica "harmoniza a exegese à tradição e à comunidade" (FRANCO, 1995, p.81). Diante de um texto, a tarefa da hermenêutica é "superar uma distância, um afastamento cultural: o que se pretende é aproximar o leitor, hoje de um texto que se torna estranho" (FRANCO, 1995, p.81). É no movimento da interpretação que o ser interpretado pode ser compreendido. 
Quando Ricoeur analisa a psicanálise, o mal ou a ideologia, o faz para "emergir o sentido humano ali implicado" (SCHAEFER, 2008, p.59). Dessa forma, Schaefer (2008), sugere que a intuição central da obra ricoeuriana da teoria da interpretação é a de mostrar que "a realidade é simbólica e o símbolo, precisa ser interpretado" (Idem, p.60). Para Japiassu:

É o símbolo que exprime nossa experiência fundamental e nossa situação no ser. É ele que nos reintroduz no estado nascente da linguagem. O ser se dá a o homem mediante as sequiências simbólicas, de tal forma que toda visão do ser, toda existência como relação ao ser, já é uma hermenêutica (JAPIASSU, 1990, p.3).

Essa centralidade no símbolo quer dizer que o homem, não se contenta com sua linguagem primária para exprimir sua experiência no mundo.

Para além da experiência das coisas e dos acontecimentos, situa-se o nível da linguagem filosófica, linguagem interpretativa capaz de revelar uma experiência ontológica que é relação do homem com aquilo que o constitui homem, vale dizer, foco do sentido (JAPIASSU, 1990, p.4).

Através da análise da linguagem, Ricoeur persegue seu objetivo de "elucidar as múltiplas funções do significar humano" (JAPIASSU, 1990), pois é através da linguagem que o filósofo francês penetra na hermenêutica. Para ele, afirma Franco (1995), “o homem é linguagem. É através da linguagem que o ser humano expressa sua curta consciência e sua visão crítica do mundo" (FRANCO, 1995, p.49). A via da interpretação é uma forma de buscar o sentido humano.

Portanto, Ricoeur é um filósofo que busca através da via da interpretação o sentido humano. "É através das mediações que o ser humano pode se compreender" (FRANCO, 1995, p.48). Ainda Franco (Ibidem), argumenta que Ricoeur, "entra pelo caminho da análise indireta do ser humano na história e na cultura. O ser humano pode ser conhecido por meio de sua linguagem" (Ibidem). Uma das formas de mediação, de via indireta para o acesso ao ser humano é o símbolo, e é uma linguagem expressa em todas as culturas.

Chamo símbolo a toda a estrutura de significação em que um sentido directo, primário, literal, designa por acréscimo um outro sentido indirecto, secundário, figurado, que apenas pode ser apreendido através do primeiro. Esta circunscrição das expressões com sentido duplo constitui precisamente o campo hermenêutico (RICOEUR, 1978, p.14).

Por ser histórico o agir humano que se expressa pela linguagem, necessita de interpretação e essa interpretação é o encontro de dois mundos. A interpretação do filósofo 
hermeneuta visa um sentido que emerge do objeto, ele "espera algo, que crê que algo se dirige a ele através da linguagem" (FRANCO, 1995, p.74). Os símbolos são manifestações de sentido, a linguagem simbólica porta um sentido, uma história que precisa ser interpretada. Por interpretação, Ricoeur, entende "o trabalho de pensamento que consiste em decifrar o sentido escondido no sentido aparente, em desdobrar os níveis de significação implicados na significação literal (RICOEUR, 1978, p.14).

Portanto, os símbolos são alimentos para a reflexão, da mesma forma, sugere-se que a cultura também é um estímulo para o pensamento e necessita de interpretação para não ser ingênua. Em sua proposta hermenêutica, Ricoeur propõe uma dialética-interpretativa. $\mathrm{O}$ caráter dialético do símbolo é visto como um jogo entre ocultar e mostrar, pois ele traz consigo um disfarce e uma revelação. Esse caráter ambíguo do símbolo é próprio de um ser de linguagem que está inserido na cultura e nela, ele cria valores e significados.

A linguagem cultural, refletida nos sinais, nos símbolos, nos costumes, nas diversas manifestações artísticas, como a dança, a música, a forma das sociedades de moldar os objetos, expressa a forma como os seres humanos fazem sua experiência de mundo em relação com os outros. O universo cultural contemporâneo, oferece o encontro entre diferentes culturas. E nesse encontro, existem possibilidades fazer experiências na forma de enculturação.

\section{Considerações Finais}

Os seres humanos são imersos no ambiente simbólico da cultura e nela, eles criam os significados para sua existência. Logo, a cultura dá o que pensar! E se ela dá o que pensar, ela precisa de interpretação, porque carrega um mundo de significados. O turismo cultural possibilita esse encontro com o outro, no entanto, esse encontro cultural se dá através das trocas de linguagem. Acontece que, por vezes, o turismo cultural transforma a cultura do destino visitado em um objeto mercadológico e o turista em um consumidor ávido por colecionar destinos. Deturpando os sentidos que estão implicados na cultura e em sua linguagem simbólica, fazendo da cultural um espetáculo.

A contribuição da hermenêutica, tal como é proposta por Ricoeur, significa captar os sentidos, revelar os significados da comunicação simbólica. O turismo cultural é uma prática, na qual, o deslocar do sujeito busca conhecer o outro, que se apresenta como novo e diferente, visando uma experiência nova. No entanto, acredita-se que o diálogo entre filosofia e turismo poderia realizar um diálogo com o turismo cultural, visto que, o ato de conhecer outra cultura seria superado pela perspectiva da interpretação e da interação cultural. 
Superar as distâncias e buscar aproximações culturais parece ser os desafios que o diálogo entre filosofia e turismo enfrenta nesse âmbito. Para isso, a compreensão se faz necessária para perceber a cultura como um ambiente simbólico e não como um ambiente que proporciona um espetáculo.

Um dos grandes desafios da filosofia é não encerrar-se num monólogo consigo, mas, estabelecer diálogos entre as áreas do saber. Nesse sentido, Paul Ricoeur oferece, através de sua hermenêutica uma forma de interpretar o sentido da linguagem simbólica. O artigo propôs uma relação entre turismo cultural e filosofia, ambas, possuem em comum o aspecto da linguagem humana como fonte e objeto de conhecimento. Superar as distâncias e buscar aproximações culturais parece ser os desafios que o diálogo entre filosofia e turismo enfrenta nesse âmbito. Para isso, a compreensão se faz necessária para perceber a cultura como um ambiente simbólico e não como um ambiente que proporciona um espetáculo.

\section{Referencias}

AVIGHI, Carlos Marcos. Turismo, globalização e Cultura. In: Lage; MILONE. Turismo: Teoria e Prática. São Paulo: Atlas, 2000. (p.102 - 106).

BARUFFA, Giovanni. A humanização cultural e sua ambivalência. In: Revista Razão e Fé (p.35-39). Pelotas: EDUCAT, 2005.

D'AGOSTINI, Franca. Analíticos e Continentais: guia à filosofia dos últimos trinta anos. São Leopoldo: UNISINOS, 2003.

DOSSE, François. $O$ império do sentido: a humanização das ciências humanas. Bauru: EDUSC, 2003.

DONAIRE, José Antonio. Turismo Cultural: entre la experiência y el ritual. Barcelona: Vitel.La, 2012.

FRANCO, Sérgio de Gouvêa. Hermenêutica e Psicanálise na obra de Paul Ricoeur. São Paulo: Edições Loyola, 1995.

JAPIASSU, Hilton. Apresentação. In: RICOEUR, Paul. Interpretação e ideologias. 4.ed. Rio de Janeiro: Francisco Alves, 1990.

RICOEUR, Paul. O conflito das interpretações: ensaios de hermenêutica. Porto: RES, 1978.

PESAVENTO, Sandra Jatahy. Cultura e Representações, uma trajetória. Revista Anos 90. v. 13, n. 23/24. Porto Alegre, 2006 (p.45-58). Disponível em:

www.seer.ufrgs.br/anos90/article/viewFile/6395/3837. Acesso dia 15 de outubro de 2016.

PÉREZ, Xerardo Pereiro. Turismo Cultural. Uma Visão Antropológica. Tenerife España: El Sauzal, 2009. 
SCHAEFER, Osmar Miguel. Sobre Hermenêutica e Filosofia. In: PIZZI, Jovino; GHIGGI, Gomercindo. (org). Diálogo crítico-educativo: um debate filosófico. Pelotas: EDUCAT, 2008.

SEGALA, Luiziane. V. Gastronomia e Turismo Cultural. Revista Turismo, 2003.

VILLAVERDE, Marcelino Agís. Paul Ricoeur: los caminos de la hermenéutica. In: Revista ÁGORA: papeles de filosofía. Vol. 25, nº 2: (p.25-44), 2006. Disponível em:

http://www.filosofiayliteratura.org/1/autores/Marcelino/Agis_Caminos_herm.pdf. Acesso dia 03 de novembro de 2017.

WICKS, Ana Escribar. La hermenéutica como camino hacia la comprensión de sí: homenaje a Paul Ricoeur. In: Revista de Filosofia. Volumen 61 (p.43-59), 2005. Disponível em: http://repositorio.uchile.cl/bitstream/handle/2250/131965/La-hermeneutica-como-caminohacia-la-comprension-de-si.pdf?sequence=1. Acesso dia 03 de novembro de 2017. 